\title{
Title: Sexual selection predicts the persistence of populations within altered environments
}

Authors: Jonathan M. Parrett ${ }^{1}$, Darren J. Mann², Arthur Y. C. Chung ${ }^{3}$, Eleanor M. Slade ${ }^{4,5 *}$ \&

$5 \quad$ Robert J. Knell ${ }^{1 *}$

1 School of Biological and Chemical Sciences, Queen Mary, University of London. Mile End Road, London E1 4NS, UK.

2 Hope Entomological Collections, Museum of Natural History, Oxford University, Oxford, U.K.

103 Forest Research Centre, Forestry Department, P.O. Box 1407, 90715 Sandakan, Sabah, Malaysia. 4 Department of Zoology, University of Oxford, South Parks Road, Oxford OX1 3PS, UK.

5 Asian School of the Environment, Nanyang Technological University, 50 Nanyang Avenue, Singapore 639798.

*Joint senior authors and authors for correspondence. Emails R.Knell@qmul.ac.uk \& eleanor.slade@ntu.edu.sg

Other author email addresses: jonathan.parrett@amu.edu.pl, darren.mann@oum.ox.ac.uk, arthur.chung@sabah.gov.my

Author contributions: JP and ES carried out the field- and lab-work, JP analysed the data and drafted the manuscript. DM advised and assisted with species identifications, AC contributed help and advice with fieldwork and permits. JP, ES and RK conceived and designed the study and ES and RK supervised the study.

Data availability: data from this study are archived on the SAFE project data repository at https://zenodo.org/record/3247492\#.XSLxFpPOI_R

Running head: Sexual selection and population persistence Manuscript statistics: Abstract 148 words, main text 4365 words, 3 figures, no tables, 89 references. 
Keywords: sexual selection, extinction, adaptation, environmental stress, oilpalm, tropical forest, Coleoptera, Scarabaeidae 


\section{Abstract}

The effect of sexual selection on species persistence is unclear. The cost of bearing ornaments or armaments might increase extinction risk, but sexual selection can also enhance the spread of beneficial alleles and increase the removal of deleterious alleles, potentially reducing extinction risk. Here we investigate the effect of sexual selection on species persistence in a community of thirtyfour species of dung beetles across a gradient of environmental disturbance ranging from oldgrowth forest to oil palm plantation. Horns are sexually selected traits used in contests between males, and we find that both horn presence and relative size are strongly positively associated with species persistence and abundance in altered habitats. Testes mass, an indicator of post-copulatory selection, is, however, negatively linked with the abundance of species within the most disturbed habitats. This study represents the first evidence from a field system of a population-level benefit from pre-copulatory sexual selection. 
Sexual selection is ubiquitous across the animal kingdom, driving the evolution of traits which give advantages in competition for matings and fertilisations (Darwin 1871; Andersson 1994). Such traits are typically costly to produce and maintain, and are often honest indicators of an individual's condition, with their degree of expression reflecting underlying genetic quality via the 'genic capture' mechanism in many cases (Rowe \& Houle 1996; Tomkins et al. 2004; Cotton \& Pomiankowski 2007). By skewing individuals' reproductive success, sexual selection has the capacity to have profound effects on the fitness and viability of populations (Holland \& Rice 1999; Lumley et al. 2015), particularly when a population faces stressful environmental change (Fricke \& Arnqvist 2007; Long et al. 2012), but the picture is a complex one with both negative and positive effects of sexual selection potentially operating at the population level (Candolin \& Heuschele 2008; Holman \& Kokko 2013).

Of the potential negative effects, the straightforward costs to individuals arising from the effects of strong sexual selection are numerous. Sexual ornaments and weapons are costly to grow and to carry (Bobek et al. 1990; Rico-Guevara \& Hurme 2018), sexual display and contests with rivals can be exceedingly expensive energetically (Hunt et al. 2004) and bring a risk of injury, and the increased conspicuousness of sexual display traits and need for movement to find potential mates can increase the risk of predation (Godin \& McDonough 2003; Kuchta \& Svensson 2014). Additionally, sexual selection reduces effective population sizes (Kokko \& Brooks 2003) and may erode genetic variation Dugand et al. 2019, but see also Radwan et al. 2016). Models incorporating this additional selection load imposed by sexual selection find that the probability of extinction can be increased (Lande 1980; Tanaka 1996; Kokko \& Brooks 2003) under certain circumstances (Martínez-Ruiz \& Knell 2017). Further to these costs of sexual selection, there are potential negative impacts at the population level arising from the effects of sexual conflict (Arnqvist \& Rowe 2005): if traits which are beneficial to the fitness of one sex act antagonistically in the other sex, causing reduced fitness, then this can 
reduce adaptation rates (Holland 2002; Rundle et al. 2006; Chenoweth et al. 2015), impede the removal of deleterious alleles (Arbuthnott \& Rundle 2012) and reduce the net reproductive rate of the population (Holland \& Rice 1999). A study of sex ratios and male harassment in common lizards Lacerta vivipara, (Le Galliard et al. 2005) suggested that sexual conflict could even cause extinction via a positive feedback loop whereby male harassment causes mortality of females, leading to a male-biased sex ratio which then causes stronger selection for aggressive males, causing further female mortality and ultimately driving the population to extinction. Modelling (Rankin et al. 2011) suggests that this scenario is indeed plausible.

By contrast, a body of other research suggests that sexual selection could have beneficial effects at the population level. Theory indicates that when there is strong reproductive skew sexual selection can increase adaptation rates to novel environments: if the skew is in favour of 'high quality' individuals this enhances the spread of adaptive alleles throughout a population (Lorch et al. 2003; Martínez-Ruiz \& Knell 2017). Consistent with this theory, laboratory studies using invertebrate model organisms in experimental evolution designs have found that sexual selection enhances adaptation and protects against extinction (Fricke \& Arnqvist 2007; Long et al. 2012; Plesnar-Bielak et al. 2012; Jacomb et al. 2016; Parrett \& Knell 2018; Yun et al. 2018). Similarly, sexual selection has also been found to enhance the removal of deleterious alleles and to reduce the probability of extinction from inbreeding depression (Jarzebowska \& Radwan 2010; Lumley et al. 2015). A recent meta-analysis of 65 laboratory experimental evolution studies found that overall there is a significant positive effect on traits associated with population fitness when sexual selection is strong, especially when under environmental stress (Cally et al. 2019).

Taken as a whole, therefore, laboratory experiments suggest that at the population level the overall effect of sexual selection is likely to be positive (Cally et al. 2019), although this will depend on the specific system, the environmental conditions (Yun et al. 2018), and the nature of genetic variation within a population (Dugand et al. 2019). Field studies, however, using comparative techniques and 
largely focussed on vertebrates, suggest that sexual selection either increases extinction risk (McLain et al. 1995; McLain \& Vives 1998; Sorci et al. 1998; Doherty et al. 2003; Morrow \& Pitcher 2003; BroJørgensen 2014; Martins et al. 2018) or has no effect on population level fitness (Prinzing et al. 2002; Morrow \& Fricke 2004). As an example, multiple studies have found that artificially introduced populations of sexually dichromatic bird species are less likely to become established on islands when compared to sexually monochromatic species (McLain et al. 1995, 1999; Sorci et al. 1998) but see also (Donze et al. 2004; Moulton et al. 2009). Taking a different approach, Martins et al. (2018) recently found that over geological timescales prehistoric ostracod species with a high intensity of sexual selection, as predicted from sexual dimorphism in both size and shape, were more likely to become extinct compared to species with relatively weak sexual selection. populations, and field studies which tend to focus on communities of vertebrates, often with small population sizes which could lead to an overriding effect of demographic stochasticity (MartínezRuiz \& Knell 2017). In order to attempt to resolve this, we examined the effect of sexual selection on the persistence of tunneller dung beetle (Scarabaeidae: Scarabaeinae) populations after the alteration and modification of tropical rainforest in Sabah, Malaysian Borneo. Beetles were sampled across a replicated gradient of habitat disturbance ranging from old growth forest (OGF) through selectively-logged (SLF) and heavily-logged forest (HLF) to oil palm plantation (OPP) (Ewers et al. 2011). Thirty-four species of tunneller dung beetle were found in the OGF, and the persistence and abundance of each of these was followed across the gradient of environmental alteration; thus we restricted the analysis to the tunneller species that were present in the undisturbed environment. The intensity of sexual selection in each species was estimated using surrogates of pre-copulatory sexual selection: whether a species is horned or hornless, and relative size of horns. Relative testes mass was also recorded as a measure of post-copulatory sexual selection. Measures such as these are used widely to estimate the intensity of sexual selection between species (Andersson 1994; 
2007, 2014; Simmons et al. 2007). We find that horn presence, and within horned species horn length, both predict species persistence and abundance across the disturbance gradient, and we find evidence linking higher testes mass to reduced abundances. 
Study sites were located within the Stability of Altered Forest Ecosystems (SAFE) project site $\left(4^{\circ} 33^{\prime} \mathrm{N}\right.$, $\left.117^{\circ} 16^{\prime} \mathrm{E}\right)$ and the Maliau Basin Conservation Area $\left(4^{\circ} 49^{\prime} \mathrm{N}, 116^{\circ} 54^{\prime} \mathrm{E}\right)$ in Sabah, Malaysian Borneo. The SAFE project is a large scale experiment investigating the effects of rainforest modification and fragmentation, consisting of a mixture of selectively logged and heavily logged lowland dipterocarp rainforest, and oil palm plantations which were planted between 2000 and 2006 (Ewers et al. 2011). The SAFE project has been specifically designed to address the large-scale effects of forest fragmentation and disturbance in a well replicated design that controls for environmental variation (see Ewers et al. 2011 for further details). Sampling of dung beetles was carried out across a gradient of forest modification: old growth forest (OGF) in Maliau Basin, and within SAFE, in twice selectively logged continuous forest (SLF), twice heavily logged forest (HLF), and oil palm plantation (OPP). The experimental fragmentation described by Ewers et al. (2011) had not yet taken place and so these 'fragments' are classified as heavily logged forest (HLF) within this study. For details in the differences in intensity of logging and forest cover between sites see Ewers et al. (2011) and for details of a number of abiotic factors see Hardwick et al. (2015). Dung beetle sampling was performed between January and February in 2011 (Slade et al. 2019) to estimate abundance and species richness across the disturbance gradient, and to collect data on horn presence and relative lengths across the community. Between July and August in 2015 sampling was carried in the same sites to collect data on testes mass and increase sample sizes for relative horn lengths across the community. In total, data from 108 traps from 2011 were used to determine species richness and abundance data across the landscape. Each habitat type (OGF, SLF, HLF, OPP) had three replicates, with nine sampling points (second order points in the sampling design explained in Ewers et al., 2011) per replicate. Spatial scaling differed in HLF (Ewers et al. 2011) and nine second order points from three replicates (Fragments B, D and E in Ewers et al. 2011) were randomly selected. In 2015 the traps 
were set at the same locations except only 3 traps were set per replicate in SLF due to logistical reasons as beetles used for testes dissections needed to be live trapped and collected within 24 hours.

In both 2011 and 2015 sampling was carried out using pitfall traps baited with 25g of human dung protected from rain with a cover. Human dung is widely used as standardised bait in tropical forests (Marsh et al. 2013) and attracts a wide variety of dung beetle species (Davis et al. 2001; Larsen et al. 2006). Trapping methods differed slightly between years; in 2011 pitfall traps were half filled with a solution of water, salt and detergent which kills beetles as they break the water surface tension and cannot escape, and traps were left for $48 \mathrm{hrs}$ before being collected. In 2015, as we were collecting beetles primarily for testes measurements, live pitfall trapping was used. A plastic funnel minimized beetle escapes and traps were collected after $24 \mathrm{hrs}$.

Specimens from 2011 were stored in 90\% ethanol and identified to species level using Boucomont (1914) and Balthasar (1963) and publications describing Bornean Scarabaeinae (e.g. Ochi 1996), and the reference collections at the Oxford University Museum of Natural History (OUMNH). Species that could not be identified were given morphospecies numbers. Specimens from 2015 were identified in the field.

Our study set out to test the persistence of species after the modification of forest habitat. Until relatively recently primary old growth forest would have dominated the majority of the landscape investigated in this study. To test for population persistence after the modification of habitat in the disturbed sites, we therefore only include species that were found in OGF in our analysis and track their persistence and abundance across the disturbance gradient. Additionally, dung beetles can be separated into ecological guilds based on their method of dung removal and nesting behaviour (Slade et al. 2007). Sexual selection is believed to operate differently within these guilds and the expression of horns is strongly associated with tunnelling, rather than ball-rolling behaviour (Emlen \& Philips 2006). Since the presence and size of horns was the main proxy for precopulatory sexual 
selection used here only tunneller species were included in the analysis. In total 34 tunneller species were included in the final dataset (supporting information Table S4). When available, average body size, composite horn length, body mass, and testes mass were calculated for each species (see supporting information for details). For a number of species we were unable to calculate morphology data due to males not being trapped and these species were therefore excluded from trait specific analysis.

Statistical analysis was carried out by fitting a series of models to species richness of horned and hornless species across the disturbance gradient. A further series of models were fitted to the abundance of species across the disturbance gradient with each sexually selected trait as an explanatory variable (species being horned or hornless, relative horn length and relative testes mass). From each series of models, model comparison was made by comparing corrected Akaike information criteria $(\triangle \mathrm{AICC})$ and we report all with non-negligible support $(\triangle \mathrm{AICc}<10$; for further details of statistical analysis see supporting information). 
Of the series of statistical models fitted to assess how the species richness of horned and hornless species changed across the disturbance gradient, two had non-negligible support $(\Delta \mathrm{AICc}<10$; supporting information Table S1). Both of these included the interaction term between habitat type and whether species were horned or hornless, indicating that the effect of disturbance on the number of species persisting depends on whether the species in question were horned or hornless (Fig. 1). The majority of the horned species found in OGF persisted in SLF but the species richness of hornless species declined markedly. Both horned and hornless species were substantially reduced in HLF when compared to OGF. Strikingly, no hornless species were found to persist into OPP, whereas 11 of the 22 horned species found in OGF persisted across the disturbance gradient into OPP.

A similar pattern emerged when the abundance of horned and hornless species was analysed across the disturbance gradient. Once again, two of the models which were fitted had non-negligible support $(\triangle \mathrm{AIC}<10)$, and both included the interaction term between habitat type and whether a species was horned or hornless (supporting information Table S2). The interaction term appears to be largely driven by hornless species having reduced abundance in SLF, in contrast to horned species which tend to maintain similar abundance to OGF (Fig. 1). A similar but weaker pattern is also observed within HLF in which the abundances of both horned and hornless species are reduced. In OPP, hornless species are no longer found, and although the abundance of many horned species is reduced compared to OGF, a number of them maintain high abundances. Qualitatively similar patterns in species abundance were observed when taking phylogenetic relatedness into account by

210 fitting phylogenetic generalised linear mixed effects models (PGLMM; see supporting information for details of molecular phylogeny). The model with the lowest AIC score included the interaction term between habitat type and whether species were horned or hornless, however AIC differed by only 3.4 between the models fitted with and without the interaction (supporting information Table S3), indicating that a component of the effect of horn presence could be attributed to closer 
phylogenetic relationships between some species. Nonetheless, there is strong support overall for the result that horned species tend to maintain higher abundances after the alteration of OGF compared to hornless species.

As is typical for dung beetles (Emlen et al. 2005), there is considerable variation between horned species in the degree of investment in horns, and this variability in relative horn size is likely to be associated with differences in the intensity of male-male competition between species (Simmons \& Tomkins 1996; Bro-Jørgensen 2007). We therefore assessed the relationship between relative horn size and abundance of horned species. Three models had non-negligible support $(\Delta \mathrm{AIC} c<10)$ and all of these included the interaction term between relative horn size and habitat type (supporting information Table S2). Overall, these models show an association between species abundance and habitat disturbance, with reduced abundance within increasingly disturbed habitats. Species with relatively large horns, however, tended to either maintain or have increased abundances compared to baseline abundances (OGF) across the disturbance gradient, whereas those species with relatively low investment in horns tended to show reduced abundance, with this effect being greatest within the most disturbed sites (HLF and OPP; Fig. 2). PGLMMs showed a similar positive association between relative investment in horns and abundance after habitat disturbance; in this case the difference between AIC scores between models fitted with and without the interaction term between habitat type and relative investment in horns was >10 (supporting information Table S3). The model coefficients indicate that species with relatively large horns maintain similar abundances to OGF within SLF and HLF, compared to species with relatively little investment in horns which tend to have reduced abundances after the habitat is modified. Overall, there is strong support for an effect of relative horn length influencing species abundance across the disturbance gradient. Moreover, those species with relatively large horns tend to persist at high abundances compared to those with little investment in horns. 
Sexual selection can also occur post-copulation and relative testes size is known to correlate strongly with the intensity of sperm competition a species experiences (Hosken 1997; Byrne et al. 2002; Simmons et al. 2007). We used relative testes mass as an estimate of the intensity of postcopulatory sexual selection. From the series of models fitted six had non-negligible support $(\triangle \mathrm{AICC}<10)$, and of these the three with the lowest $\triangle \mathrm{AICC}$ scores included the interaction term between testes mass and habitat type (supporting information Table S2). These models suggest that species with relatively large testes have reduced abundance in HLF and OPP compared to species with relatively small testes, with no effect of testes mass on species abundance in OGF and SLF, although this effect is hard to visualise (Fig. 3). The remaining three models with non-negligible support, however, do not show this same relationship: one retains the main effects of habitat and testes mass and the remaining two just the main effect of habitat, indicating that the degree of support for an effect of relative testes mass on species abundance across the disturbance gradient is less than the support for effects of horn presence and relative horn length (see above). The PGLMM containing the interaction term between relative testes mass and habitat type was the best fitting and the difference in AIC scores was 4.9 between the models with and without the interaction term included (supporting information Table S3). The model estimates indicate similar effects as nonphylogenetic models: species with relatively large testes have reduced abundance in HLF and OPP compared to their abundances in SLF, however, in the least disturbed habitats (OGF \& SLF) there was no effect of testes mass on species abundance. Together these results indicate some support for a negative effect of relative testes mass on species persistence within the most disturbed habitats. 
As the intensity of disturbance increases species associated with old growth forest (OGF) are progressively lost, with those remaining tending to have reduced abundances. Such patterns have been observed in dung beetle communities before (Slade et al. 2011; Braga et al. 2013; Gray et al. 2014; França et al. 2017) and are likely to be a common pattern across a wide variety of taxa (Sodhi et al. 2004; Gardner et al. 2009; Bicknell et al. 2014; Thorn et al. 2018). Here we find evidence that this loss of species with disturbance is reduced in horned species. Furthermore, within the horned species there is an effect of relative horn size, whereby a high degree of investment in horns is associated with larger population sizes and improved persistence after habitat modification. We also find a negative relationship between relative testes mass and abundance, although only in the two most disturbed habitats.

Our findings that species possessing horns and, if horned, those species with relatively large horns have increased persistence across the disturbance gradient are largely consistent with theoretical predictions (Lorch et al. 2003; Martínez-Ruiz \& Knell 2017) and the majority of laboratory studies (Cally et al. 2019) which suggest that sexual selection acts to purge populations of deleterious alleles and drive adaptive evolution. On the basis of this theory, we can propose a mechanism for this pattern. Expression and exaggeration of horns is known to be condition dependent in dung beetles (Emlen 1994; Knell \& Simmons 2010), and so those males with the largest horns are likely, on average, to be better adapted to the environment or to be carrying a lower mutational load than others. In those species that express horns, intrasexual competition is likely to be more intense compared to hornless species, and in those species with a relatively high investment in horns it is likely to be more intense compared to those with a relatively low investment in horns. This increased intensity of competition is likely to lead to well-adapted males or those with low mutational loads, as signalled by their large horns, being able to monopolise mating opportunities (Hunt \& Simmons 2001; Karino et al. 2005; Pomfret \& Knell 2006). Sexual selection therefore could be skewing 
reproductive success in favour of 'high quality' individuals, providing population-level benefits of competition between males and increasing the likelihood that species under strong pre-copulatory sexual selection are more likely to persist after environmental change.

The population-level benefits of male-male competition found here contrast with the finding that relative horn length in bovids is positively associated with extinction risk (Bro-Jørgensen 2014), and these data are also apparently at odds with a number of previous field studies, which found sexual selection to increase the probability of extinction in novel environments (McLain et al. 1995, 1999; Sorci et al. 1998). A number of possible explanations exist for this discrepancy. For example, before habitat alteration, the populations in the current study would probably have been at or near their natural carrying capacities, whereas many previous studies focussed on the persistence of small or very small populations of introduced birds (McLain et al. 1995, 1999; Sorci et al. 1998). It has been suggested that strong sexual selection could make small populations such as the ones addressed in these studies of birds particularly prone to extinction due to increased demographic stochasticity, whereas large populations would benefit from strong sexual selection (Martínez-Ruiz \& Knell 2017), which is consistent with the current study. Furthermore, generation time can influence the adaptive capacity of populations (Chevin et al. 2010). Although little is known about generation times for the animals studied here, dung beetles typically have short development times (Simmons \& Kotiaho 2002), and therefore increased potential to adapt compared to those previous studies on species with relatively long generation times such as birds and mammals (McLain et al. 1995, 1999; Sorci et al. 1998; Doherty et al. 2003) - it is possible that this increased adaptive capacity could interact with the strength of sexual selection to enhance population persistence.

The patterns we describe could, alternatively, arise if horned species are able to outcompete hornless species, and if species with relatively large horns outcompete those with relatively small horns for resources within habitats which are structurally less complex (i.e. disturbed habitats). Indeed, within the mite, Rhizoglyphus echinopus, aggressive male morphs have been shown to 
outcompete benign male morphs in less complex habitats (Tomkins et al 2011). Although we cannot explicitly reject this idea it seems unlikely in this case for several reasons. Firstly, in dung beetles the majority of interspecific resource competition will occur between females, which rarely express horns. Secondly we are unaware of any literature indicating that horns (male or female) in dung beetles are used in interspecific competition, and thirdly, although the ecological complexity is, overall, greater in the least disturbed sites, the actual space in which resource competition will be occurring (i.e. a dung pile or tunnel) is likely to remain similar between habitats.

In contrast to the positive effects of pre-copulatory sexual selection, we found a negative effect of relative testes mass on species abundance within the most disturbed habitat types. Like horns, testes mass can be condition-dependent in dung beetles (Knell \& Simmons 2010; Almbro \& Simmons 2014) and this is likely to be the case within the species studied here. Male animals are known to trade-off investment in traits associated with pre-copulatory success against traits associated with post-copulatory success (Simmons et al. 2017), so this pattern could potentially arise if horn size and/or presence is negatively correlated with testes mass. In other tunnelling dung beetles the evolution of longer horns has been found not to be associated with reductions in testes mass (Simmons \& Fitzpatrick 2016). Additionally, in our dataset mean testes mass did not differ between horned and hornless species, and within the horned species there is no evidence for a relationship between horn length and testes mass (see supporting information). This indicates that the observed negative relationship between testes mass and abundance is not likely to simply be an artefact of the relationship between investment in horns and testes.

This negative relationship is, however, consistent with the findings that increased sperm competition and polyandry, predicted from testes size in birds (Morrow \& Pitcher 2003) and sexual dimorphism in ostracods (Martins et al. 2018), are positively associated with extinction risk and extinction, respectively. In line with previous work, this finding highlights the possibility of trait-specific costs and benefits (Morrow \& Pitcher 2003; Bro-Jørgensen 2014). For example, if horned, dung beetle 
species with larger testes are predicted to have increased proportions of 'minor' males adopting alternative mating strategies (Simmons et al. 2007), this is likely to reduce reproductive skew in male populations and possibly negate the beneficial effects of pre-copulatory sexual selection in this system. It is also possible that the increased level of polyandry associated with larger testes may decrease levels of paternal provisioning (Ball et al. 2017) and reduce the reproductive potential of stressed populations further.

The negative relationship between testes mass and abundance could also arise if increased mating rates and levels of sperm competition reduce female fitness via harmful male traits such as seminal fluids (Chapman 2001) or mechanical damage (Arnqvist et al. 2005) and therefore reduce overall population fitness (Holland \& Rice 1999). Although we do not know the strength of sexual conflict in the species studied here it seems an unlikely explanation for this observation because in Onthophagus taurus, a congeneric of many of the species in the current study, there is little evidence of strong sexual conflict, with multiple female matings leading to higher female fitness (Simmons \& García-González 2008; Garcia-Gonzalez \& Simmons 2011; Simmons \& Holley 2011). This is the first study of wild populations to find a positive effect of pre-copulatory sexual selection at the population-level and find evidence indicating that species with increased intensity of malemale competition are more likely to persist after modification of the environment. Understanding which species may be particularly prone to extinction after environmental change is important when evaluating species conservation status and management practices. Due to sexual selection being ubiquitous in sexually reproducing species, further knowledge of its influence on population fitness within our rapidly changing world is becoming increasingly important. 


\section{Acknowledgements}

We thank Sol Milne and the Land use Options for Maintaining BiOdiversity and eKosystem functions (LOMBOK) Project research assistants for their assistance in the field. Glen Reynolds and SEARRP, The Stability of Altered Forests Ecosystems Project, The Maliau Basin Management Committee, and the Sabah Biodiversity Council, Malaysia, for their support in obtaining permits and research permissions. EMS acknowledges funding from a British Ecological Society Small Ecological Project Grant, No.: 3256/4035, and the Varley-Gradwell Travelling Fellowship in Insect Ecology. EMS is supported by a UK Natural Environment Research Council grant (NE/K016407/1; http://lombok.hmtf.info/). JMP was supported by a QMUL postgraduate studentship and is thankful for funding awarded by QMPGRF. Samples were collected under Permit No. EPU Ruj. UPE: 40/200/19/2712 and SaBC access licence number JKM/MBS.1000-2/2(381) to EMS and JMP, project number RS 302 under the Royal Society SEARRP, and Project No. 129 under MBMC. We also thank Rosie Drinkwater and Steve Rossiter for their help and advice with the phylogenetic work. Finally, we are grateful to Gene Hunt and two anonymous reviewers whose constructive criticism greatly improved a previous draft of the manuscript. 


\section{References}

Almbro, M. \& Simmons, L.W. (2014). Sexual selection can remove an experimentally induced mutation load. Evolution, 68, 295-300.

Andersson, M. (1994). Sexual selection. Princeton University Press, Princeton, USA.

Arbuthnott, D. \& Rundle, H.D. (2012). Sexual Selection Is Ineffectual or Inhibits the Purging of Deleterious Mutations in Drosophila melanogaster. Evolution, 66, 2127-2137.

Arnqvist, G., Nilsson, T. \& Katvala, M. (2005). Mating rate and fitness in female bean weevils. Behav. Ecol., 16, 123-127.

Arnqvist, G. \& Rowe, L. (2005). Sexual conflict. Princeton University Press, Princeton, NJ.

Ball, A.D., van Dijk, R.E., Lloyd, P., Pogány, Á., Dawson, D.A., Dorus, S., et al. (2017). Levels of extrapair paternity are associated with parental care in penduline tits (Remizidae). Ibis , 159, 449455.

Balthasar, V. (1963). Monographie der Scarabaeidae und Aphodiidae der palaearktischen und orientalischen Region. Verlag, Prague.

Bicknell, J.E., Struebig, M.J., Edwards, D.P. \& Davies, Z.G. (2014). Improved timber harvest techniques maintain biodiversity in tropical forests. Curr. Biol., 24, R1119-20.

Bobek, B., Perzanowski, K. \& Weiner, J. (1990). Energy Expenditure for Reproduction in Male Red Deer. J. Mammal., 71, 230-232.

Boucomont, A. (1914). Les coprophages de l'archipel malais. Annales de la Société Entomologique de France, 83, 238-350.

Braga, R.F., Korasaki, V., Andresen, E. \& Louzada, J. (2013). Dung beetle community and functions along a habitat-disturbance gradient in the Amazon: a rapid assessment of ecological functions associated to biodiversity. PLoS One, 8, e57786.

Bro-Jørgensen, J. (2007). The intensity of sexual selection predicts weapon size in male bovids. Evolution, 61, 1316-1326.

Bro-Jørgensen, J. (2014). Will their armaments be their downfall? Large horn size increases extinction risk in bovids. Anim. Conserv., 17, 80-87.

400 Byrne, P.G., Roberts, J.D. \& Simmons, L.W. (2002). Sperm competition selects for increased testes mass in Australian frogs. J. Evol. Biol., 15, 347-355.

Cally, J.G., Stuart-Fox, D. \& Holman, L. (2019). Meta-analytic evidence that sexual selection improves population fitness. Nat. Commun., 10, 2017.

Candolin, U. \& Heuschele, J. (2008). Is sexual selection beneficial during adaptation to environmental change? Trends Ecol. Evol., 23, 446-452.

Chapman, T. (2001). Seminal fluid-mediated fitness traits in Drosophila. Heredity, 87, 511-521.

Chenoweth, S.F., Appleton, N.C., Allen, S.L. \& Rundle, H.D. (2015). Genomic Evidence that Sexual Selection Impedes Adaptation to a Novel Environment. Curr. Biol., 25, 1860-1866.

$410 \quad$ Environment: Towards a Predictive Theory. PLoS Biol., 8, e1000357.

Cotton, S. \& Pomiankowski, A. (2007). Sexual selection: does condition dependence fail to resolve the "lek paradox"? Curr. Biol., 17, 335-337.

Darwin, C. (1871). The descent of Man and selection in relation to sex. John Murray, London.

Davis, A.J., Holloway, J.D., Huijbregts, H., Krikken, J., Kirk-Spriggs, A.H. \& Sutton, S.L. (2001). Dung beetles as indicators of change in the forests of northern Borneo. J. Appl. Ecol., 38, 593-616.

Doherty, P.F., Sorci, G., Royle, J.A., Hines, J.E., Nichols, J.D. \& Boulinier, T. (2003). Sexual selection affects local extinction and turnover in bird communities. Proc. Natl. Acad. Sci. U. S. A., 100, 5858-5862.

Donze, J., Moulton, M.P., Labisky, R.F. \& Jetz, W. (2004). Sexual plumage differences and the outcome of game bird (Aves: Galliformes) introductions on Oceanic Islands. Evolutionary Ecology Research, 6, 595-606.

Dugand, R.J., Tomkins, J.L. \& Kennington, W.J. (2019). Molecular evidence supports a genic capture 
resolution of the lek paradox. Nat. Commun., 10, 1359.

Emlen, D.J. (1994). Environmental-Control of Horn Length Dimorphism in the Beetle Onthophagus acuminatus (Coleoptera, Scarabaeidae). Proceedings of the Royal Society B: Biological Sciences, 256, 131-136.

Emlen, D.J., Marangelo, J., Ball, B. \& Cunningham, C.W. (2005). Diversity in the weapons of sexual selection: horn evolution in the beetle genus Onthophagus (Coleoptera: Scarabaeidae). Evolution, 59, 1060-1084.

430 Emlen, D.J. \& Philips, T.K. (2006). Phylogenetic evidence for an association between tunneling behavior and the evolution of horns in dung beetles (Coleoptera: Sacarabaeidae: Scarabaeinae). Coleopterists society monograph, 5, 47-56.

Ewers, R.M., Didham, R.K., Fahrig, L., Ferraz, G., Hector, A., Holt, R.D., et al. (2011). A large-scale forest fragmentation experiment: the Stability of Altered Forest Ecosystems Project. Philos. Trans. R. Soc. Lond. B Biol. Sci., 366, 3292-3302.

França, F.M., Frazão, F.S., Korasaki, V., Louzada, J. \& Barlow, J. (2017). Identifying thresholds of logging intensity on dung beetle communities to improve the sustainable management of Amazonian tropical forests. Biol. Conserv., 216, 115-122.

Fricke, C. \& Arnqvist, G. (2007). Rapid Adaptation to a Novel Host in a Seed Beetle (Callosobruchus maculatus): The Role of Sexual Selection. Evolution, 61, 440-454.

Garcia-Gonzalez, F. \& Simmons, L.W. (2011). Good genes and sexual selection in dung beetles (Onthophagus taurus): genetic variance in egg-to-adult and adult viability. PLoS One, 6, e16233.

Gardner, T.A., Barlow, J., Chazdon, R., Ewers, R.M., Harvey, C.A., Peres, C.A., et al. (2009). Prospects for tropical forest biodiversity in a human-modified world. Ecol. Lett., 12, 561-582.

Godin, J.-G.J. \& McDonough, H.E. (2003). Predator preference for brightly colored males in the guppy: a viability cost for a sexually selected trait. Behav. Ecol., 14, 194-200.

Gray, C.L., Slade, E.M., Mann, D.J. \& Lewis, O.T. (2014). Do riparian reserves support dung beetle biodiversity and ecosystem services in oil palm-dominated tropical landscapes? Ecol. Evol., 4, 1049-1060.

450 Hardwick, S.R., Toumi, R., Pfeifer, M., Turner, E.C., Nilus, R. \& Ewers, R.M. (2015). The relationship between leaf area index and microclimate in tropical forest and oil palm plantation: Forest disturbance drives changes in microclimate. Agric. For. Meteorol., 201, 187-195.

Holland, B. (2002). Sexual Selection Fails to Promote Adaptation to a New Environment. Evolution, $56,721-730$.

Holland, B. \& Rice, W.R. (1999). Experimental removal of sexual selection reverses intersexual antagonistic coevolution and removes a reproductive load. Proc. Natl. Acad. Sci. U. S. A., 96, 5083-5088.

Holman, L. \& Kokko, H. (2013). The consequences of polyandry for population viability, extinction risk and conservation. Philos. Trans. R. Soc. Lond. B Biol. Sci., 368, 20120053.

Hosken D. J. (1997). Sperm competition in bats. Proceedings of the Royal Society of London. Series B: Biological Sciences, 264, 385-392.

Hunt, J., Brooks, R., Jennions, M.D., Smith, M.J., Bentsen, C.L. \& Bussière, L.F. (2004). High-quality male field crickets invest heavily in sexual display but die young. Nature, 432, 1024-1027.

Hunt, J. \& Simmons, L.W. (2001). Status-dependent selection in the dimorphic beetle Onthophagus taurus. Proceedings of the Royal Society of London B: Biological Sciences, 268, 2409-2414.

Jacomb, F., Marsh, J. \& Holman, L. (2016). Sexual selection expedites the evolution of pesticide resistance. Evolution, 70, 2746-2751.

Jarzebowska, M. \& Radwan, J. (2010). Sexual selection counteracts extinction of small populations of the bulb mites. Evolution, 64, 1283-1289.

470 Karino, K., Niiyama, H. \& Chiba, M. (2005). Horn length is the determining factor in the outcomes of escalated fights among male Japanese horned beetles, Allomyrina dichotoma L. (Coleoptera: Scarabaeidae). J. Insect Behav., 18, 805-815.

Knell, R.J. \& Simmons, L.W. (2010). Mating tactics determine patterns of condition dependence in a 

2353.

Kokko, H. \& Brooks, R. (2003). Sexy to die for? Sexual selection and the risk of extinction. Ann. Zool. Fennici, 40, 207-219.

Kuchta, S.R. \& Svensson, E.I. (2014). Predator-mediated natural selection on the wings of the damselfly Calopteryx splendens: differences in selection among trait types. Am. Nat., 184, 91109.

Lande, R. (1980). Sexual dimorphism, sexual selection and adaptation in polygenic characters. Evolution, 34, 292-305.

Larsen, T.H., Lopera, A. \& Forsyth, A. (2006). Extreme trophic and habitat specialization by Peruvian dung beetles (Coleoptera: Scarabaeidae: Scarabaeinae). Coleopt. Bull., 60, 315-325.

Le Galliard, J.-F., Fitze, P.S., Ferrière, R. \& Clobert, J. (2005). Sex ratio bias, male aggression, and population collapse in lizards. Proc. Natl. Acad. Sci. U. S. A., 102, 18231-18236.

Long, T.F., Agrawal, A.F. \& Rowe, L. (2012). The effect of sexual selection on offspring fitness depends on the nature of genetic variation. Curr. Biol., 22, 204-208.

Lorch, P.D., Proulx, S., Rowe, L. \& Day, T. (2003). Condition-dependent sexual selection can accelerate adaptation. Evol. Ecol. Res., 5, 867-881.

Lumley, A.J., Michalczyk, Ł., Kitson, J.J.N., Spurgin, L.G., Morrison, C.A., Godwin, J.L., et al. (2015). Sexual selection protects against extinction. Nature, 522, 470-473.

Marsh, C.J., Louzada, J., Beiroz, W. \& Ewers, R.M. (2013). Optimising bait for pitfall trapping of Amazonian dung beetles (Coleoptera: Scarabaeinae). PLoS One, 8, e73147.

Martínez-Ruiz, C. \& Knell, R.J. (2017). Sexual selection can both increase and decrease extinction probability: reconciling demographic and evolutionary factors. J. Anim. Ecol., 86, 117-127.

Martins, M.J.F., Puckett, T.M., Lockwood, R., Swaddle, J.P. \& Hunt, G. (2018). High male sexual investment as a driver of extinction in fossil ostracods. Nature, 556, 366-369.

McLain, D.K., Moulton, M.P. \& Redfearn, T.P. (1995). Sexual Selection and the Risk of Extinction of Introduced Birds on Oceanic Islands. Oikos, 74, 27-34.

McLain, D.K., Moulton, M.P. \& Sanderson, J.G. (1999). Sexual selection and extinction: the fate of plumage-dimorphic and plumage-monomorphic birds introduced onto islands. Evol. Ecol. Res., 1, 549-565.

McLain, D.K. \& Vives, S.P. (1998). Sexual Selection and Community Structure: An Island Biogeographic Analysis with Beetles. Oikos, 82, 271-281.

Morrow, E.H. \& Fricke, C. (2004). Sexual selection and the risk of extinction in mammals. Proceedings of the Royal Society B: Biological Sciences, 271, 2395-2401.

Morrow, E.H. \& Pitcher, T.E. (2003). Sexual selection and the risk of extinction in birds. Proc. Biol. Sci., 270, 1793-1799.

Moulton, M.P., McLain, D.K. \& Moulton, L.E. (2009). Sexual selection and the fate of introduced pigeons and doves (Aves: Columbidae). Evol. Ecol. Res., 11, 889-904.

Ochi, T. (1996). Studies on the family Scarabaeidae (Coleoptera) from Borneo 1. Identification keys to subfamily, tribes and genera. Giornale Italiano di Entomologia, 8, 37-54.

Parrett, J.M. \& Knell, R.J. (2018). The effect of sexual selection on adaptation and extinction under increasing temperatures. Proc. R. Soc. B, 285, 20180303.

Plesnar-Bielak, A., Skrzynecka, A.M., Prokop, Z.M. \& Radwan, J. (2012). Mating system affects population performance and extinction risk under environmental challenge. Proceedings of the Royal Society of London B: Biological Sciences, 279, 4661-4667.

Pomfret, J.C. \& Knell, R.J. (2006). Sexual selection and horn allometry in the dung beetle Euoniticellus intermedius. Anim. Behav., 71, 567-576.

Prinzing, A., Brändle, M., Pfeifer, R. \& Brandl, R. (2002). Does sexual selection influence population trends in European birds? Evol. Ecol. Res., 4, 49-60.

Radwan, J., Engqvist, L. \& Reinhold, K. (2016). A Paradox of Genetic Variance in Epigamic Traits: Beyond "Good Genes" View of Sexual Selection. Evol. Biol., 43, 267-275. 
Rankin, D.J., Dieckmann, U. \& Kokko, H. (2011). Sexual conflict and the tragedy of the commons. Am. Nat., 177, 780-791.

Rico-Guevara, A. \& Hurme, K.J. (2018). Intrasexually selected weapons. Biol. Rev. Camb. Philos. Soc. Rowe, L. \& Houle, D. (1996). The lek paradox and the capture of genetic variance by condition dependent traits. Proc. Biol. Sci., 263, 1415-1421.

Rundle, H.D., Chenoweth, S.F. \& Blows, M.W. (2006). The Roles of Natural and Sexual Selection During Adaptation to a Novel Environment. Evolution, 60, 2218-2225.

Simmons, L., Emlen, D. \& Tomkins, J. (2007). Sperm competition games between sneaks and guards: a comparative analysis using male beetles. Evolution, 61, 2684-2692.

Simmons, L.W. \& Fitzpatrick, J.L. (2016). Sperm competition and the coevolution of pre-and postcopulatory traits: Weapons evolve faster than testes among Onthophagine dung beetles. Evolution, 70, 998-1008.

Simmons, L.W. \& García-González, F. (2008). Evolutionary reduction in testes size and competitive fertilization success in response to the experimental removal of sexual selection in dung beetles. Evolution, 62, 2580-2591.

Simmons, L.W. \& Holley, R. (2011). Offspring viability benefits but no apparent costs of mating with high quality males. Biol. Lett., 7, 419-421.

Simmons, L.W. \& Kotiaho, J.S. (2002). Evolution of ejaculates: patterns of phenotypic and genotypic variation and condition dependence in sperm competition traits. Evolution, 56, 1622-1631.

Simmons, L.W., Lüpold, S. \& Fitzpatrick, J.L. (2017). Evolutionary Trade-Off between Secondary Sexual Traits and Ejaculates. Trends Ecol. Evol.

Simmons, L.W. \& Tomkins, J.L. (1996). Sexual selection and the allometry of earwig forceps. Evol. Ecol., 10, 97-104.

Slade, E.M., Bush, E., Mann, D.J. \& Chung, A.Y.C. (2019). Dung beetle community and dung removal data 2011. DOI: https://zenodo.org/record/3247492\#.XRyyw497k2w

Slade, E.M., Mann, D.J. \& Lewis, O.T. (2011). Biodiversity and ecosystem function of tropical forest dung beetles under contrasting logging regimes. Biol. Conserv., 144, 166-174.

Slade, E.M., Mann, D.J., Villanueva, J.F. \& Lewis, O.T. (2007). Experimental evidence for the effects of dung beetle functional group richness and composition on ecosystem function in a tropical forest. J. Anim. Ecol., 76, 1094-1104.

Sodhi, N.S., Koh, L.P., Brook, B.W. \& Ng, P.K.L. (2004). Southeast Asian biodiversity: an impending disaster. Trends Ecol. Evol., 19, 654-660.

Sorci, G., Møller, A.P. \& Clobert, J. (1998). Plumage dichromatism of birds predicts introduction success in New Zealand. J. Anim. Ecol., 67, 263-269.

Tanaka, Y. (1996). Sexual selection enhances population extinction in a changing environment. J. Theor. Biol., 180, 197-206.

Thorn, S., Bässler, C., Brandl, R., Burton, P.J., Cahall, R., Campbell, J.L., et al. (2018). Impacts of salvage logging on biodiversity: A meta-analysis. J. Appl. Ecol., 55, 279-289.

Tomkins, J.L., Radwan, J., Kotiaho, J.S. \& Tregenza, T. (2004). Genic capture and resolving the lek paradox. Trends Ecol. Evol., 19, 323-328. mates and the improvement of nonsexual fitness. Proc. Natl. Acad. Sci. U. S. A. 
Figures

570
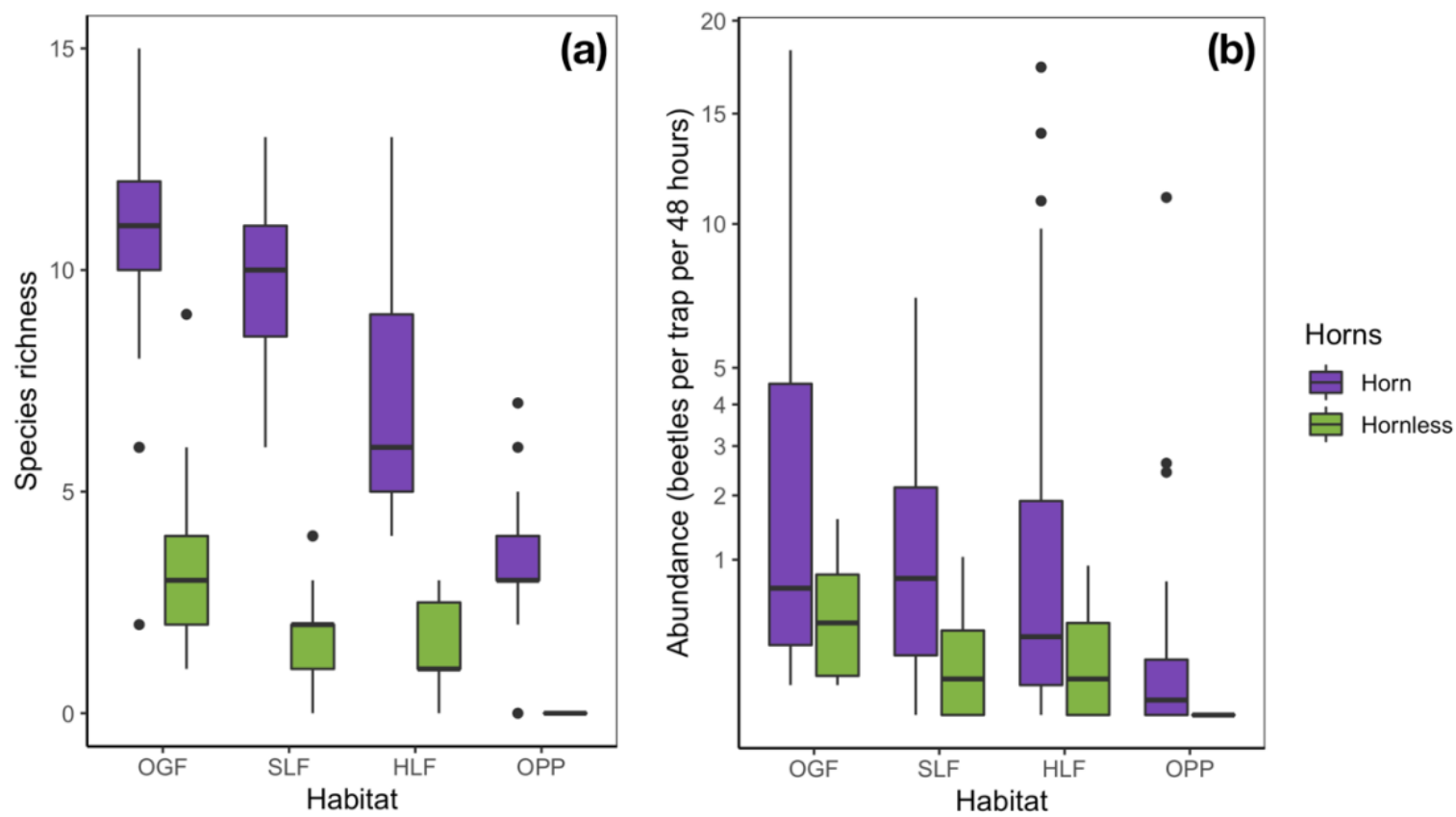

Figure 1: The effect of species being horned or hornless on (a) species richness and (b) abundance of species in each trap across the disturbance gradient: old growth forest (OGF), selectively logged forest (SLF), heavily logged forest (HLF), and oil palm plantation (OPP). The y-axis in $b$ is on a square-root scale to improve visualisation of data. 


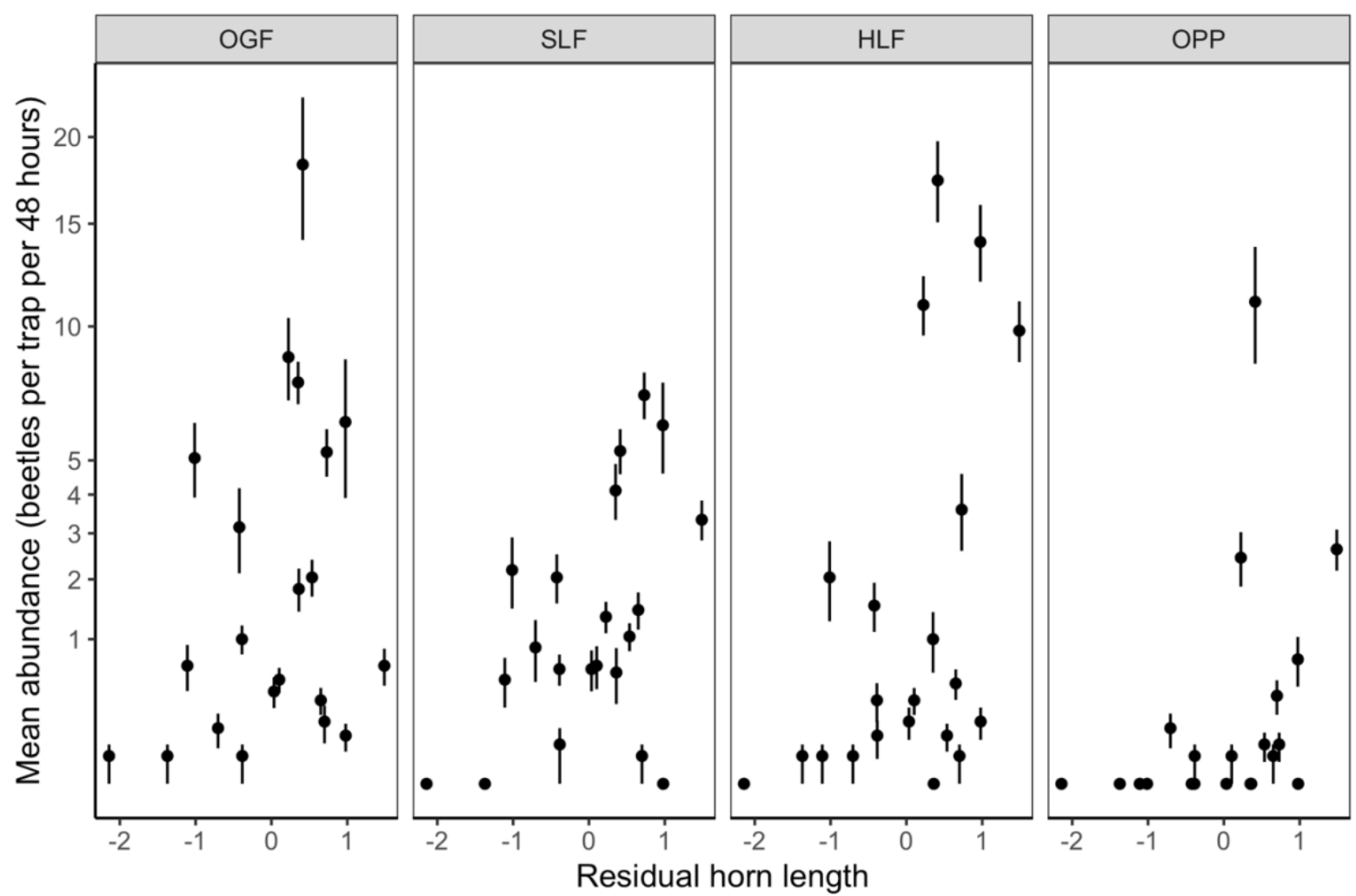

Figure 2: The effect of investment in horns after controlling for the effect of body size (residual horn size from a log-log transformed regression of horn length on body size, used here for illustrative purposes) on the mean abundance of species per trap across the disturbance gradient: old growth forest (OGF), selectively logged forest (SLF), heavily logged forest (HLF), and oil palm plantation (OPP). The y-axis is on a square-root scale to improve visualisation of data and error bars indicate SE. 

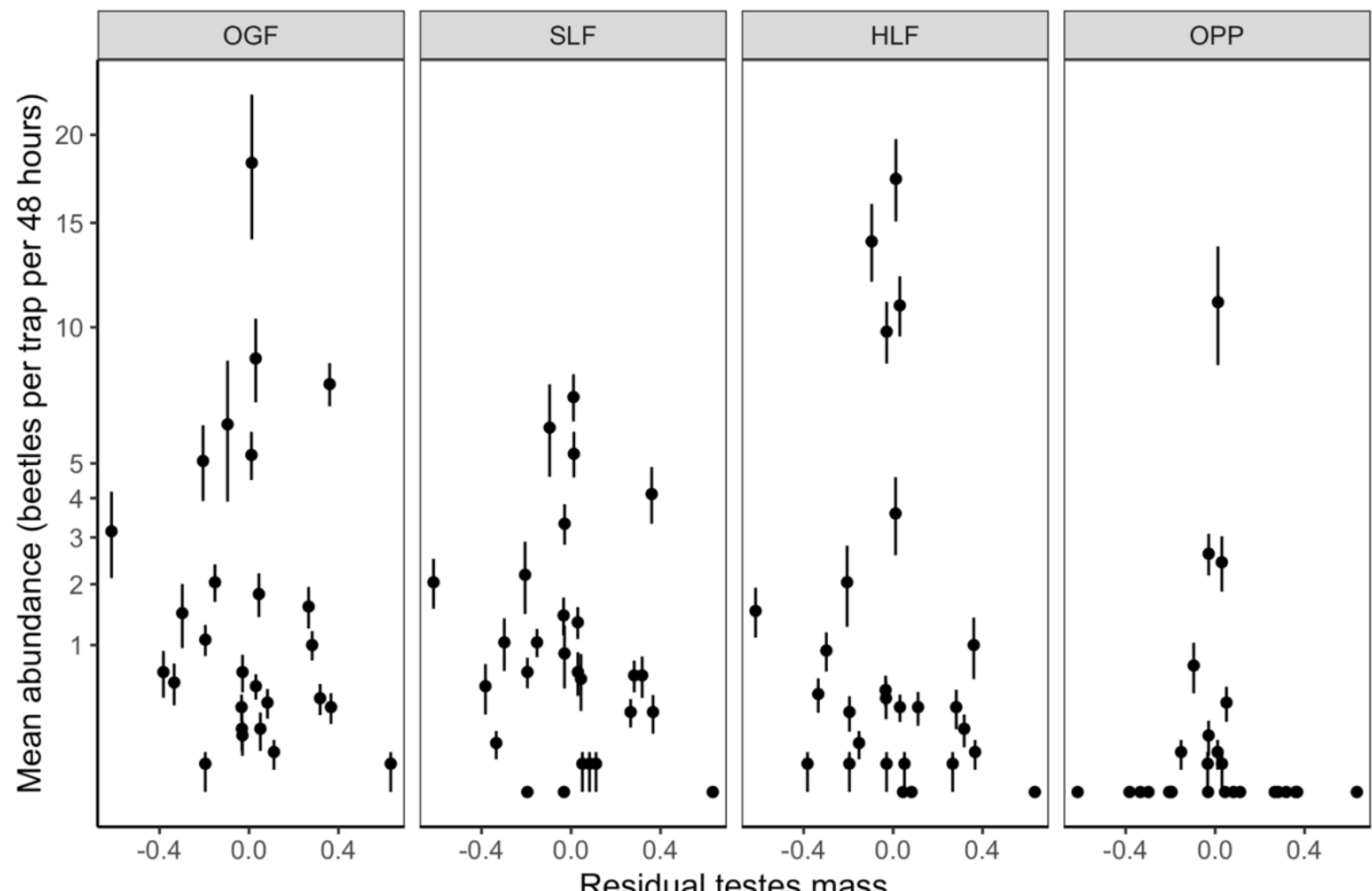

Figure 3: The effect of testes mass after controlling for effect of body mass on the mean abundance of species per trap across the disturbance gradient: old growth forest (OGF), selectively logged forest (SLF), heavily logged forest (HLF), and oil palm plantation (OPP). The y-axis is on a square-root scale to improve visualisation of data and error bars indicate SE. As for fig. 2, residual testes mass from a log-log regression of testes mass on total body mass is used to represent relative testes mass for illustrative purposes only. 